\title{
The Barcelona Mobile Cluster: Actors, Contents and Trends
}

\author{
$\underline{\text { doi:10.3991/ijim.v3i3.814 }}$ \\ C. A. Scolari ${ }^{1}$, H. Navarro Güere ${ }^{1}$, I. García ${ }^{1}$, H. Pardo Kuklinski ${ }^{1}$ and J. Soriano ${ }^{2}$ \\ ${ }^{1}$ Universitat de Vic, Vic, Spain \\ ${ }^{2}$ Universitat Autónoma de Barcelona, Barcelona, Spain
}

\begin{abstract}
Communication mediated by mobile devices is one of the most dynamic sectors of the global economy and is transforming different aspects of our lives, including our ways of relating and our cultural production, distribution and consumption models. Media studies should not ignore these transformations. This paper presents the results of a study carried out during 2008 to determine the actors, contents produced and trends of the mobile communication companies in Barcelona. The study outlines an initial map of the situation, proposes a series of analysis categories and lays the foundations for more specific future studies on mCommunication.
\end{abstract}

Index Terms-mCommunication, mobile communication, mobile marketing, mobile gaming, Barcelona

\section{INTRODUCTION}

The web has brought new challenges to traditional mass communication studies. Mass communication theories, founded in the broadcasting logic, have undergone an upheaval since the new forms of interactive communication, that combine different media, formats and languages, arrived [1]. When these processes started to become part of research agendas, and the web was just starting to take off, a new medium began to forge a path in the communication ecosystem: mobile devices.

It is now possible to say that the digitalization of the content production and distribution processes and worldwide diffusion of the Internet was only the first stage of an evolution that is far more extensive and complex. The second phase of communication digitalization has begun with two very clear trends:

- The traditional model of communication media, based on the diffusion concept (one-to-many) has been challenged by the appearance of new collaborative logics (many-to-many) [2] [3].

- The diffusion of portable communication devices able to connect to the Internet as terminals and to receive and transmit all kinds of digital contents has opened the doors to what is now called the 'mobile Internet' [4] [5].

From the 90s the mobile telephone has undergone a remarkable transition in its evolution process: it has stopped being an instrument of interpersonal communication for an elite group of professionals to become a multifunctional product of the masses that connects to the Internet as one more terminal. This leads us to consider the appearance of a new form of communication: mobile communication (mCommunication).

\section{A. The Relevance of mCommunication}

According to the studies carried out by the International Telecommunications Union in September 2007 there were more than 3,300 million mobile telephones in the world (in 2000 this figure was only 800 thousand) [6]. In Spain there are 50,548,312 mobile telephone lines including those associated with computers $(+6.2 \%$ compared to April 2007). For every 100 inhabitants, $44.5 \%$ have landlines but $109.1 \%$ have mobiles [7]. No other communication medium or device has reached this level of penetration in society.

This diffusion of mobile devices has caused a repositioning of the large economic and technologic actors. All of the Spanish companies involved in the sector, from the telecommunication operators to those who produce contents, consider mCommunication as a new frontier for their business activities [8] [9] [10]. In this extremely dynamic, global context, the city of Barcelona has become a very relevant location. The Mobile World Congress (ex 3GSM World Congress) has been held in this city for four consecutive years (2006-2009), which has favored the public visibility of many local companies and their integration into international projects and networks. The Mobile World Congress is one of the most important conferences in the world of mobile phones. It is a huge commercial and networking initiative created by the GSM Association, an organization that brings together more than 700 GSM operators (Global System for Mobile Communications) in 220 countries with more than 170 associated members.

Every day there is an increasing number of scientific books and articles produced on mCommunication, mainly in the United States, Northern Europe and Asia, and it is evident that the Spanish academic world is lagging behind. Among the work on mobile communication in Spain we can mention the pioneer analysis on the impact of new media [11] or more recent studies from the perspective of media studies [12] [13] [14]. In Catalonia, there are few research works on mCommunication from the perspective of media studies; among these it is worth noting the analysis of journalism via MMS that uses the service provided by the newspaper La Vanguardia as a case study [15]. The growing importance of Barcelona and Catalonia in mCommunication demands a more in-depth study of the business and communication dynamics within this geographic area.

\section{B. Towards a Definition of mCommunication}

mCommunication is a social practice of content production/consume and technological appropriation carried out through the massive diffusion of multifunctional wireless 
devices. The diversification of the technology (mobile communication devices now incorporate an increasing number of functions, from cameras to music players, web navigators or mini consoles for videogames) and the extended range of terminals (mobile telephones, palmtops, smartphones, iPods, etc.) has generated the support for mCommunication.

The telephone has evolved from being a one-to-one communication device, and has adopted new forms that are already used in the Internet (one-to-many, many-tomany, etc.). The third generation mobile devices incorporate different communication modes, from the most massive and public (receiving television) to the most personal (sending and receiving SMS messages). Between these two modes there are a wide range of possible communication and exchange forms that no other technical device offers in the same way. To some degree, the new generation of mobile devices is closer to personal computers than traditional telephones; this is why they can also be considered a metamedium, which is a concept that certain researchers have used to refer to the web [16].

In synthesis we can say that mCommunication is a phenomenon within the confluence of a series of properties and functions:

- Ubiquity and the ability to be carried (communication anywhere, anytime)

- Convergence of functions, media and languages (metamedium)

- Integration of communication models (broadcasting, unicasting, multicasting, etc.)

- Bidirectionality (consumption and production of contents)

- Contents and services designed according to localization.

\section{OBJECTIVES AND RESEARCH METHODOLOGY}

There is no need to discuss the importance of mCommunication: mobiles are now part of the media system and will soon be considered simply 'one more medium' like television or radio. Until recently, research into the mobile device sector has mainly taken the form of applied technical studies (studies based on the development of hardware or software for the functioning of these devices), sociological studies (investigating the uses and the social impact) or economic analyses (studies of the mobile telephone market, commercial strategies and business models). There is also research that analyzes mCommunication from the media studies perspective [17]; however, in Catalonia there is practically no research into this sector from this point of view. The general objective of this study was to analyze mobile communication in Catalonia from the media studies perspective. Therefore, an initial map of the economic actors, contents, services and trends of the mobile communication sector in Catalonia was constructed. As all the companies are located in and around the city of Barcelona we prefer to define this reality as the 'Barcelona Cluster'.

\section{A. Methodology}

For some time now there have been scientific observations, long-term studies, longitudinal surveys, registers and periodic audits of the mass communication media in Catalonia that evidence the size and evolution of the sec- tor; however, in the case of content production for mobiles there are few data sources of this style. For this research an initial exploratory empirical study was carried out and information was gathered directly from the sector. This implied becoming familiar with a very little known phenomenon and therefore the research team drew up a flexible work plan in order to deal with the different aspects that could arise during the study [18].

The research team's first objective was to identify the actors who could be reliable information sources in order to outline the map of the sector in Catalonia. The Chamber of Commerce and specialized publications were consulted although the main source of information was the Mobile World Congress. When the work began in October 2007 we had a list of 84 companies, among which were the most outstanding content and services producers in Catalonia.

The sampling carried out to select the interviewees combined elements of both quota and snowball sampling, neither of which are probabilistic. The sample size, which was finally 23 interviewees, was determined by the type of content produced (journalism, publicity, etc.). Each of these production sectors had a different number of interviews depending on the number of businesses in the market and the information saturation point of the interviews:

- Marketing and publicity contents (7 companies: Ubiqua, Frog Mobile Services, Tempos 21, Mobbiz Communication, CPM Telecom Publitono, AdsMedia, Daem Interactive)

- Education and services contents (6 companies or institutions: Ajuntament de Barcelona [The Barcelona Council], Digital Work Force, e-movilia, Childtopia, Bluethchannel, Ta with You)

- Audiovisual and videogame contents (5 companies: Digital Legend Entertainment, Kailab, Lechill Mobile, Cromosoma, Microjocs)

- Journalistic contents (4 companies: CCRTV Interactiva, La Vanguardia/Grup Godó, Agència Catalana de Notícies, Vilaweb)

- User-generated contents (1 company: Ready People).

The requisite for the interviewees was that they were in charge of content production.

The study was enriched by subjective information from experts in the sector, their opinions, experiences and expectations by combining structured and semistructured interview modes in a single questionnaire that included different aspects (open and closed questions and objective data on the company). The interviews lasted between 30 and 90 minutes.

The analytic process was based on the intersection between the productive sectors and analytic categories in order to outline descriptions that cover the entire sector. This allowed us to observe the behavior of the categories beyond their productive specialties. This information process was complemented with an exhaustive study of bibliographic sources, statistics on the mCommunication market and information from specialized publications.

\section{THE mCOMMUNICATION ACTORS IN CATALONIA}

In this section we present the results obtained in the research on the content and service producers for mobile communication in Catalonia. 


\section{A. Company Profiles}

Most of the companies analyzed are private initiatives. The exceptions are three cases of public journalism institutions or companies that later incorporated content and service production for mobile communication (Ajuntament de Barcelona, CCRTV Interactiva and the Agència Catalana de Notícies [Catalan News Agency]).

Most of the people interviewed have a university degree in engineering and/or multimedia. The professional origin of the actors differed depending on the production sector. For example, in the case of mobile marketing (mMarketing) there were publicists, copywriters and media planning experts. The role of journalists is decisive in the creation of information contents for mobile devices and therefore the task of programmers is relegated to second place; however, in the videogame sector, programmers play a very important part.

\section{B. The Size of the Companies}

The highest number of permanent workers in these companies fluctuated between 20 and 25 people. However, in the case of companies that were already established before they entered the mobile market and in which content production for mobiles is only a part of the main activity (for example, journalistic companies), there is generally no more than 10 professionals dedicated to mCommunication.

In other sectors, like the production of low-cost videogames or contents for mMarketing, it is also not strange to find companies with no more than 10 employees. Having a small number of permanent personnel gives these small companies a great capacity to adapt to the needs of the market. The only exceptions to this model are the 'fusions' with or acquisitions by large companies.

\section{The Size of the Projects}

On one hand there are companies that carry out simple short-term projects (from one to six months), for example low-cost videogames or mMarketing platforms. Due to the characteristics of there markets they need to respond immediately to the client's needs, especially publicity agents or operators; some small companies have been able situate themselves very well in this type of project. On the other hand, there are companies that specialize in complex, long-term projects (from 12 to 18 months) that require a group of very specialized professionals and a high level of coordination.

How do the companies manage these projects? Flexibility seems to be the key concept for understanding their capacity to adapt to the market's rhythm. The companies that carry out different short-term projects need to work together in parallel. Often these companies are precisely those with the fewest employees, and therefore the situation is always critical, as they may carry out up to six products at the same time.

\section{The Fusion Myth}

In such a dynamic market as that of mCommunication it is possible that a company with few employees can be absorbed by a large company with diversified business models on a global scale. Many young enterprises wish to the bought by a larger company. This discourse, which could be defined as the myth of fusion, emerged in many of the interviews we carried out, mainly for the mMarket- ing and videogame companies. Why do we say 'myth'? Because many business people, although they vindicate their independence and capacity to adapt quickly to the client's demands as a result of their small size, really aspire to fuse with a larger company.

One of the paradigmatic cases of fusion, widely referred to by the interviewees, is the case of Digital Chocolate buying the company Microjocs. The global expansion of Digital Chocolate has not been limited to Catalonia, they have also bought a studio in Helsinki (Finland) and a programming company in Bangalore (India). These fusions, that really have little to do with 'fusing' as the large company buys the small one, have not led to any radical changes in the production routines of the bought company: the company that buys the other company is looking for precisely this, a particular way of designing and producing contents.

This model reproduces a organizational form already tested successfully in many other sectors of the economy (automobile industry, electrical appliance industry, etc.) in which the business headquarters is located in the United States, the design is carried out in Europe and the production in countries with low labor costs.

\section{E. Multiskilling and Outsourcing}

In the companies with few employees, which is the majority in the sample studied, the employees assume various tasks. One person interviewed defined it as an 'adaptable, amorphous structure'. This is not a new situation: multiskilling is common in digital communication companies in Catalonia [19] [20].

Unlike other production centers, Barcelona has little outsourcing: Catalan companies prefer to concentrate their production in their own territory. However, in certain sectors such as the mMarketing sector there are some companies who work for large foreign publicity agencies. These are global or national companies that need a videogame or contents specifically for mobiles as part of a multimedia publicity strategy. Some small companies from Barcelona have successfully found a niche in this area, making Catalonia a receiver rather than a generator of outsourcing.

\section{F. Company Models, Business Models}

Two different company profiles became clear during the research:

- Companies of recent origin created after 2000 that were formed exclusively for mobile communication (native companies);

- Consolidated companies that incorporated the mobile media into their traditional products after the year 2000 (migrant companies).

Native companies predominate in the sample studied here. Although there are few migrant companies, they contribute significantly to the content production. Native companies tend to be formed by a group of young professionals who decided to work together, or as a new company within a larger one that is consolidated in another sector (computing, audiovisual, etc.). Most of the companies that operate in the mMarketing area belong to the first group, and there is one example of the second type in the audiovisual sector.

Migrant companies are companies that come from other markets, for example audiovisual production, journalism 
or the Internet, which have included contents for mobile communication devices in the products they offer. Journalistic companies predominate in this group, as they use this new channel as another platform for spreading information content. In most cases the production for mobiles is an appendage to the contents designed for the Internet, and in this sense these companies still do not have a mature business model.

Both models are found in the videogame sector, from companies created for designing games for consoles and computers that migrate to the mobile sector to companies created for producing interactive contents for mobile communication devices.

In the context of conforming to a new market, it stands out that the contents offered by many new, independent, private producers is based on a single product (monoproduct phase). Nearly all of the enterprises interviewed were created with this format, generally based on SMS messages, and they then broadened their services, continually adapting to the constant changes of the market (MMS, advergames, clips, etc.) (diversification phase).

\section{G. The Company Network}

In saturated markets, for example the editorial or television markets, it is very difficult for new actors to break in. However, the opposite is true for the mobile communications sector: the difficulty here lies in the fact that there is no consolidated market with established actors with shared game rules. This is why it is very difficult to find a place in an ecosystem that is still in its initial construction phase. Both the native and migrant companies have original business proposals that involve a high degree of experimentation and commercial uncertainty. It is common for small companies to establish periodic tactical alliances in accordance with the demands of the moment to carry out more ambitious projects and/or offer more services to their clients.

The model of the company network that Castells [21] describes fits this dynamic. It is an:

\section{[...] organizational form constructed around a busi- ness project, which results from the cooperation be- tween different components of various companies that operate in a network while a certain business project lasts; the networks are reconfigured to complete each project' (pp. 84).}

In the interviews carried out various enterprises from the videogame and marketing sectors highlighted this aspect of their production dynamic. The flexibility to grow without losing control of the production process is one of the most essential characteristics of Castells' model and the work method of the companies interviewed, especially the native companies. Identifying this small swarm of multiskilled, flexible companies that can adapt to the permanently mutating market has been one of the most notable discoveries of this study.

\section{H. An Operator-Dependant Model}

Another aspect that stands out and which conditions the functioning of these companies is the central role of the mobile network operators (Movistar, Vodafone, Orange, etc.) through the construction of what are known as walled gardens. The interviewees complained of the operators' excessive influence on the market and the way in which this conditions the evolution of their products. The great majority of the current business models are operatordependent, which leaves the small companies at the mercy of the large telecommunication companies. This generates great uncertainty for the companies interviewed.

The way to escape from this is to diversify clients and products. The companies that find themselves tied to mobile network operators know that the solution is to develop different types of contents and services for other buyers. For example, a company that worked exclusively for Nokia developed one of the first videogames for Apple's iPhone 3G; other companies diversify their clients and attempt to produce for the television industry, editorial groups or larger companies in the mobile sector. This situation is starting to change with the appearance of $3 \mathrm{G}$ devices and Mobile Internet, since in these new scenarios the content producers do not depend exclusively on the operators to offer services to the users.

\section{Economic Actors: General Situation}

Most of the interviewees recognized that they are new actors with little experience in the mCommunication business and that they operate in an expanding industry in its initial stages. The large migrant companies that come from the journalism and audiovisual sectors and who have recently entered mCommunication are also in this situation. The 'new medium', both technologically and culturally, is currently in a process of construction in which constant experimentation dominates most of the business practices.

However, not all the areas within the mobile communication sector in Barcelona are in the same economic situation. While some recognize the relative immaturity of the market and note the limited amount of business, others feel that there are more and more possibilities every day. For example, the videogame industry is now in a very good moment, with a very competitive professional environment, clients who bring a large amount of business and enormous possibilities to continue growing. After the videogame industry comes mMarketing, a sector that is becoming profitable and whose actors are confident will become a very lucrative business very soon given that the market is opening up quickly. Further behind we find the currently loss-making journalism market. The audiovisual sector and the sector of user-generated contents (mobile web 2.0), except for some exceptions of contents for an adult public, have almost inexistent economic turnover in Catalonia.

For the companies interviewed, the fact that the Mobile World Congress is held in Barcelona is essential for promoting the visibility of their companies and constructing international networks. This event is a commercial beacon for launching many Catalan companies and products and an enormous opportunity that other Spanish or European communities do not have.

\section{IV. mCOMMUNICATION CONTENTS AND SERVICES IN CATALONIA}

\section{A. Journalism Contents and Services}

Since the year 2000 the main Catalan journalistic companies provide information services through mobile communication devices. The expectations for the new medium have led these companies to create contents, but always as 
an appendage to the contents produced for the Internet. In most cases this has inhibited the creation of structures exclusively for content production for mobiles and therefore has multiplied the tasks of ciberjournalists.

The contents chosen for mobile devices can be defined perfectly as service journalism, as the journalistic content is adapted to the way mobile users consume information. The main contents are weather forecasts, sports results, political events, etc.. Interpretive journalistic practices and opinions are not included in information production.

Among the formats most used are SMS alerts sent to subscribers (based on push technology) and the contents that are available online 24 hours a day that users can consult when they wish (pull technology). Together with some pioneering experiences in the video sector (see 4.4.), the alert services and WAP portals are the only journalistic content created specifically for mobile devices in Catalonia.

The alerts are brief and immediate, written in a telegram style like news headlines. The alert format blurs the boundary between journalistic information and service information. They are sent to subscribers who have signed up to receive this information periodically. The communication groups analyzed in this study who offer alert services send about 30 messages every month. For the managers interviewed, the main added value of this format is its immediacy. That is, the users, normally influential people in the economic and political worlds, can access current news items as soon as they happen, and can therefore act on this information immediately. At the moment this is the only service that generates revenue, as there are no profits from advertising in this sector.

The importance and speed with which the alert news is spread can be represented by a pyramidal hierarchy: first for mobiles (quick, instantaneous, short, spread quickly), then for the web (where the journalist has to spend more time writing up the news item) and lastly in the traditional media such as newspapers (where journalists write a more detailed, elaborate article).

The WAP format has become bogged down after its initial burst of activity at the end of the 90s. This is due to the high hopes producers have for the $3 \mathrm{G}$ and $4 \mathrm{G}$ technologies, as they offer better connectivity and more features.

The main companies in this sector -CCRTV Interactiva, Vilaweb and La Vanguardia- are also important actors in the diffusion of news content over the Internet, which confirms the subordinate nature of content production for mobile devices in relation to the web, which itself was subordinate, even until very recently, to the traditional media (printed press, television, etc.).

\section{B. mMarketing: Products and Services for Advertisement}

mMarketing is defined as the use of mobile platforms for sending messages (SMS, MMS), downloading applications or surfing the web for interactive publicity purposes. mMarketing is included in publicity campaigns as it favors client loyalty, improves the brand's image, encourages repeated buying, directs buyers to the selling point and establishes a new communication channel between the user and the brand. Among the contents most diffused in the media are company logos, wallpapers, audio publicity jingles or files, SMS, MMS, watermarks, advergames and brandgames, WAP portals, etc. [22] [23] [24].

All the companies studied produce their own contents and have their own platforms to manage and carry out this activity. This way the companies offer their products and services to the clients but it is the clients who manage the platform and follow the campaigns.

Some companies produce content exclusively for mobiles (SMS, MMS, advergames, etc.) while others are publicity or consultancy agencies that produce content for mobiles and other channels (polifunctional agencies).

Almost all the companies studied agree that currently SMS is the leader in publicity campaigns. SMS has become the killer application of mMarketing thanks to its low cost and technological simplicity as all mobile devices on the market can send and receive this type of message. If the rates are changed it is probable that SMS will be replaced by MMS, but at the moment the cost of these messages in Spain depends on the success or failure of this type of advertising. In this context, Bluetooth technology is increasingly used as it allows the user to access contents and download them for free, as well as produce contents and services based on the user's location (events, train stations, airports, etc.).

\section{Mobile Gaming}

Mobile Gaming (mGaming) is the result of a technological development which combines consolidated experiences and product lines. The first pre-installed game in a mobile phone was Snake, a classic for portable consoles which Nokia introduced in some of its models in 1998. Today the market has diversified and it is possible to access videogames from a wide range of wireless communication devices (PSP, Nintendo DS, iPods, smartphones, etc.). Catalan companies are very dynamic actors in this sector. Entertainment products designed in Barcelona have gained international recognition on various occasions.

There are two types of production: on one hand, there are the companies that produce low-cost games over a short time period (less than six months), and therefore the quality of the graphics and plot is not very high; and on the other hand, there are the companies that design more elaborate, high-quality games - for example, using 3D and motion capture systems - which can take up to 18 months to produce. According to the interviewees the success of the game does not depend so much on the graphic quality or the time employed to produce it but on other factors such as playability, being culturally in tune with the public, and the publicity strategies the operators apply.

The speed of production depends on different factors, from the complexity of the game to the structure of the company, as well as the number of versions (not forgetting the market's many different standards) and deadlines. As in the mMarketing sector, videogame producers are very creative and in most cases the work-teams are small and flexible and can adapt to the clients' demands and the current trends. Except for some specific cases, each game is an independent production and not a version of a famous game designed previously for wireless consoles or home technologies.

The people interviewed during this study debate between designing high-quality games and producing games quickly that end up feeding the operators' content offer. In this second sector videogame and marketing platforms 
overlap. Examples of this kind of hybrid product are Girl Finder and Lynx FX designed by Kailab for the Lynx campaigns in the United Kingdom. These types of campaigns include spots, advertisements in the press, videogames and contents for mobiles, videos in Youtube, etc. and are an example of transmedia narrative [25] applied to marketing.

One of the most sophisticated videogames produced in Catalonia is One, designed by Digital Legends for Nokia's $\mathrm{N}$-Gage device. This fighting game was created using an innovative $3 \mathrm{D}$ technology with real combatants and motioncapture processes, as well as the possibility to participate in a virtual arena with players from all over the world. Other companies such as Microjocs-Digital Chocolate are based in retrogaming, that is, they convert classic videogames into a format for mobiles, among the most successful are Movi Domino (2006) and Movi Futbolín (2006). Other popular, widespread videogames for mobiles produced in Catalonia are The Lord of the Rings (Microjocs), Fernando Alonso Racing (Gaelco Móviles), and Rafa Nadal Tennis (Virtual Toys).

\section{Mobile Television}

According to the North American researcher Amanda Lotz [26] television is expanding 'outside the box'. Kumar [27] considers that mobile television:

'[...] is emerging as the killer application of the $21^{\text {st }}$ century [...] Mobile TV, the newest addition to the mobile services portfolio, is a sunrise technology with a potential user base of over 200 million by 2011' (pp. xiiii).

However, it is a peculiar fact that people talk a lot about mobile television ( $m T V$ ), and construct hypotheses about its impact [28], but very few people actually watch it. Why? Because the offer of audiovisual content specifically for mobile devices is in its initial stages and is very under developed compared to the production of videogame, journalistic and publicity content.

In Catalonia the audiovisual content for mobiles, for example in mobisodes, trailers, and fictional and nonfictional clips produced especially for mobiles, is very limited and only works well for certain genre, such as content for adults. Contradictory attitudes to mTV emerged in the interviews: some companies keep it in mind, attentively follow its evolution and produce some contents in order to understand the dynamics of this new channel; however, other companies are distrustful and even resistant to the idea.

A Catalan company holds a predominant place in the generation of contents for adults, which is adapted from other media, generally television or cinema. The adaptation work consists in reducing the productions to short clips of about three minutes and reframing the scenes to improve their visibility on the small mobile screens.

Another emerging sector in Catalonia is the production of clips adapted from television. The CCRTV experience called TV3minutes is a pioneer in this area. The Catalan public entity, through CCRTV Interactiva, produces short, three-minute videos that summarize the television news Telenoticies, weather forecast or some of the main fictions such as Ventdelplà or El Cor de la Ciutat.

The child public is absent from the strategies of the companies interviewed. Catalonia has always been at the forefront of this communication area, from editorial production to audiovisual and interactive content; however, this sector has characteristics that limit specific contents being produced. The contents produced for children are usually not in tune with the image the mobile phone has in schools and the family. The companies that produce contents for children want to protect their reputation by not producing for this 'new' medium, as mobile devices could end up sharing some of the negative connotations that have always been associated with television.

\section{E. Institutional Information Contents}

Most of the Catalan public institutions that took part in this study do not create contents specifically for mobile devices: they generally limit themselves to adapting the contents that they produce for other formats (web or paper) or that they have bought from external companies. The contents for mobile devices in this sector, which are similar in some ways to journalistic contents, can be text, photographs, audiovisual and may even be interactive. Currently, public organizations carry out experimental and educational work so that users become used to using this channel and discover the advantages it offers.

Like in mMarketing and journalism, SMS is currently the format used most, as it costs little and has few technical problems. Examples are educational content for university students designed by one of the companies interviewed, public service contents, the Ajuntament de Barcelona's information service, for example information on public transport (timetables, delays, agenda, directory, $\mathrm{BCN}$ guide, How to get to, etc.), and cartographical services that use GPS technology and maps. These contents and their corresponding distribution platforms are bought from third parties; within Barcelona Council the team that generates the information services for mobile devices is the same that designs the contents for the Internet.

\section{F. User-Generated Contents}

The convergence between technical aspects and consumption practices has led to the hybridization of mobile devices and the web 2.0 [2] [3] to generate a new space called mobile web 2.0 [29] [30]. If the mobile Internet defines using the Internet on mobile devices, the mobile web 2.0 refers to using and producing content via mobile devices in social networks and in all Internet applications in which the contents are generated by the users.

In Catalonia this market is still in its initial stages; there are currently only three companies in this sector. The predominant business model is based on constructing virtual communities, for example for businesspeople, members of the university community [31] or for users interested in entertainment uses. However, these developments are still in a very early phase and there is no relevant economic turnover.

\section{G. Contents and Services: General Situation}

As the research advanced a clear taxonomy of contents for mobile devices began to appear: specific, adapted and non-adapted contents. Specific contents are created especially for mobile devices, while adapted contents, which generally come from the web or television, are transformed in order to be distributed through this new channel; finally, non-adapted contents arrive directly to the mobile device without having been transformed. 
If we apply this classification to the production of contents for mobile devices in Catalonia, we find the following panorama: there is extensive production of videogames and specific mMarketing contents, while journalistic and audiovisual production falls into the category of adapted contents (for example, CCRTV Interactiva's fictional and non-fictional productions and the videos for adults). None of the companies interviewed produces nonadapted contents.

Before ending this section we would like to highlight the recombination of different genre and the appearance of hybrid products. In many cases the boundary between a videogame and a marketing product is blurry. Many marketing strategies are decidedly transmediatic and include videogames for mobiles, MMS, videos on Youtube, traditional advertisements and television spots.

\section{CONCLUSION}

The objective of this work was to create a situation map of the cluster of actors, contents and trends in mobile communication in Catalonia. Considering the transformations that this sector is undergoing, this initial map provides a general panorama that should be extended in more detail with more specific studies and/or comparisons with other realities.

Although the current situation in Spain trails behind other societies in which mCommunication is extremely widespread (i.e. South Korea, Japan, Finland, etc.), Barcelona, thanks to the Mobile World Conference and the development of a network of small companies that create contents and services, is slowly entering the world map of mobile communication. Like the other countries that are more advanced in this sector, Catalonia is in a dynamic and exciting moment in history.

From the perspective of communication studies mobile devices can be considered the 'new' new media, with all the theoretical, methodological and epistemological consequences that derive from this. Due to its newness, recent mobile communication is now entering the media studies agenda; however, it is necessary for it to become a more integral part of the research into traditional or interactive media. In this context, this study of mobile communication in Catalonia is in its initial stages.

Various possible directions for future work have emerged during this research. We would like to point out two aspects that we consider relevant:

1) To carry out their projects, the companies, especially the small ones, need to adopt flexible work forms that promote multiskilling and interchanging roles. In certain sectors such as mGaming or mMarketing the smallest companies usually create collaborative networks (Castells' 'company network') depending on the projects they are undertaking. This work model deserves to be examined in more detail in future studies.

2) A more in-depth study of the new hybrid formats that goes beyond the classification proposed here (specific contents, adapted and non-adapted contents) is necessary. In this study we observed that sometimes the boundary between a videogame and a marketing product is blurry. Many communication strategies are decidedly transmediatic and include videogames for mobiles, MMS, videos on Youtube, traditional advertisements and television spots. Future research should examine in more depth the narrative structures and the multimodal meaning strategies that are being generated.

Research into mCommunication from the media studies perspective has only just begun and has a long way to go. To follow this path it is necessary to understand that a new communication medium has entered the cultural industry, a medium with its own business models, grammar, production practices and consumption dynamics. The aim of this study was to make an initial approach to the production of contents and services for mobile devices in Barcelona. With this objective we have elaborated a series of analytic categories (native company/migrant company, monoproduct phase/diversified phase, adapted/nonadapted/specific contents, etc.) that allow us to begin to understand the dynamics of this sector of the cultural industry.

This first exploratory study should be followed by others that examine some of the open research lines and incorporate others. Unlike other historic moments, for example the birth of cinema, media studies already has the theoretical, methodological and analytical elements for studying the appearance and development of a new 'species' within the media system. The consequences of this apparition will be felt in the entire communication system, which makes it necessary to include mobile communication in the agendas of researchers and any other related area, from consultant agencies to the entities that establish the sector's policies.

\section{REFERENCES}

[1] C. Scolari, Hipermediaciones. Elementos para una teoría de la comunicación digital interactive, Barcelona: Gedisa, 2008.

[2] T. O'Reilly, What Is Web 2.0 Design Patterns and Business Models for the Next Generation of Software, 2005. Online version: http://www.oreillynet.com/pub/a/oreilly/tim/news/2005/09/30/wha t-is-web-20.html

[3] C. Cobo Romaní and H. Pardo Kuklinski, Planeta Web 2.0. Inteligencia colectiva o medios fast food, Barcelona / México DF: Grup de Recerca d'Interaccions Digitals, UVic / Flacso México, 2007.

[4] D. Steinbock, Wireless Horizon. Strategy and Competition in the Worldwide Mobile Marketplace, New York: Amacom, 2003.

[5] D. Steinbock, The Mobile Revolution, London/Philadelphia: Kogan Page, 2005.

[6] International Telecommunications Union, Mobile Cellular Suscribers, 2007. Online version: http://www.itu.int/ITUD/icteye/DisplayCountry.aspx ? countryId $=73$

[7] CMT - Comisión del Mercado de las Telecomunicaciones, Nota Mensual - Abril 2008. Online version: http://www.cmt.es/

[8] GAPTEL - Grupo de Análisis y Prospectiva del Sector de las Telecomunicaciones, Contenidos Digitales. Nuevos Modelos de Distribución Online. Madrid: Red.es, 2006. Online version: http://observatorio.red.es/estudios/documentos/ContenidosDigitale s final.pdf

[9] Fundación Telefónica, La sociedad de la información en España 2007 - Resumen Ejecutivo. Madrid: Fundación Telefónica, 2007. Online version:http://sie07.telefonica.es/

[10] V. Reding "La tecnología de la información y la comunicación: motor de la economía moderna" in Nuevo paradigma de los medios de comunicación en España. Madrid: Nueva Economía Forum / Forum Europa, 2007.

[11] A. De Miguel and R. Barbeito, El impacto de la telefonía móvil en la sociedad española. Madrid; Tabula Ikonika, 1997.

[12] D. Parra, "Internet móvil como nuevo canal de información especializado" in M. Cebrián Herreros and D. Bartolomé Crespo (eds.) Investigación sobre medios de comunicación/ Medienforschung, Seminarios Internacionales Complutense, pp. 147-55, Madrid: Servicio de Publicaciones UCM, 2002. 
[13] J. M. Aguado and I. Martínez, "El proceso de mediatización de la telefonía móvil: de la interacción al consumo cultural" in Zer, 20, 2006, pp. 319-43.

[14] F. Vacas Aguilar (2007) "Telefonía móvil: la cuarta ventana” in Zer, 23, 2007, pp. 199-217.

[15] M. Avià and E. Castelló "Periodisme i Internet mòbil: un cas de servei informatiu via MMS: 'El día en cinco imágenes' de 'La Vanguardia", in Anàlisi: Quaderns de comunicació i cultura, 31, pp. 123-48, 2004.

[16] F. Colombo, "La comunicazione sintetica" in G. Bettetini and F. Colombo (eds.) Le nuove tecnologie della comunicazione, Milan: Bompiani, 1996, pp. 265-97.

[17] J. Groebel, E. Noam and V. Feldmann, Mobile Media. Content and Services for Wireless Communication, Mahwah, NJ: Lawrence Erlaboum Associates, 2006.

[18] A. Laramée and B. Vallée, La recherche en communication. Éléments de méthodologie, Québec: Presses de l'Université de Québec, 1991.

[19] C. Scolari, J. Micó, H. Navarro and H. Pardo Kuklinski, Nous perfils professionals de l'actual panorama informatiu, audiovisual i multimèdia de Catalunya, Vic (Spain): Eumogràfic, 2006.

[20] C. Scolari, J. Micó, H. Navarro and H. Pardo Kuklinski, "El periodista polivalente. Transformaciones en el perfil del periodista a partir de la digitalización de los medios audiovisuales catalanes" in Zer, 25, 2008, pp. 37-60.

[21] M. Castells, La galaxia Internet: Reflexiones sobre Internet, empresa y sociedad, Barcelona: Plaza y Janés, 2001.

[22] T. Ahonen, T. Kasper and S. Melkko, 3G Marketing: Communities and Strategic Partnerships, Chichester: John Wiley and Sons, 2004.

[23] R. Mathieson, Branding Unbound; The Future of Advertising, Sales, and the Brand Experience in the Wireless Age, New York: Amacom, 2005.

[24] T. Weiss, Mobile Strategies: Understanding Wireless Business Models, MVNOs and the Growth of Mobile Content, London: Futuretext, 2006.

[25] H. Jenkins, Convergence Culture: Where Old and New Media Collide, New York: New York University Press, 2006.

[26] A. Lotz The Television Will Be Revolutionized, New York: New York University Press, 2007.

[27] A. Kumar Mobile TV: DVB-H, DMB, 3G Systems and Rich Media Applications, Burlington, MA: Elsevier, 2007.
[28] S. Orgad, This Box Was Made for Walking... How will mobile television transform viewers' experience and change advertising?, London: London School of Economics and Political Science/Nokia, 2006. Online version: http://www.lse.ac.uk/collectio ns/pressAndInformationOffice/PDF/Mobile_TV_Report_Orgad.p df

[29] A. Jaokar and T. Fish, Mobile Web 2.0: The Innovator's Guide to Developing and Marketing Next Generation Wireless/Mobile Applications, London: Futuretext, 2006.

[30] H. Pardo Kuklinski, J. Brandt and J. Puerta, "Mobile Web 2.0. Marco teórico y tendencias de desarrollo en la industria de la comunicación móvil', V Colóquio Brasil-Espanha de Ciências da Comunicação, Brasilia, Brasil, 28-30 August 2008,

[31] H. Pardo Kuklinski and J. Brandt, "Campus Móvil: designing a mobile Web 2.0 startup for higher education uses", 5th International Conference on Social Software - BlogTalk Conference, Cork, Ireland, 3-4 March 2008.

\section{AUTHORS}

Carlos A. Scolari (carlos.scolari@ uvic.cat) is professor and co-ordinator of the Digital Interactions Research Group - Universitat de Vic (Catalonia - Spain).

Héctor Navarro Güere (hector.navarro@uvic.cat) is professor and researcher of the Digital Interactions Research Group - Universitat de Vic (Catalonia - Spain).

Irene García (irene.garcia2@uvic.cat) is professor and researcher of the Digital Interactions Research Group Universitat de Vic (Catalonia - Spain).

Hugo Pardo Kuklinski (hugo.pardo@uvic.cat) is professor and researcher of the Digital Interactions Research Group - Universitat de Vic (Catalonia - Spain).

Jaume Soriano (jaume.soriano@uab.cat) is professor (Universitat Autònoma de Barcelona) and researcher of the Digital Interactions Research Group - Universitat de Vic (Catalonia - Spain).

This work was supported by the Consell de l'Audiovisual de Catalunya (CAC) and the Universitat de Vic.

Submitted, January, 29, 2009. Published as resubmitted by the authors on June, 29, 2009. 